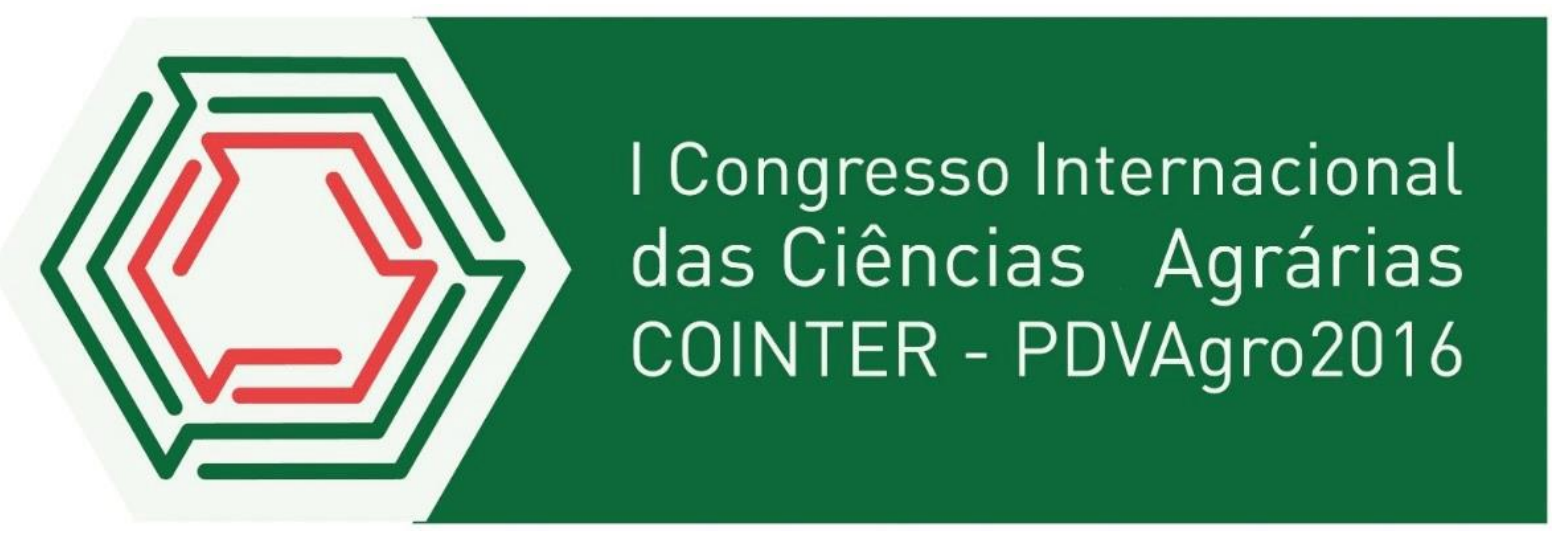

\title{
ACIDENTE DE TRABALHO NO MEIO RURAL: ANÁLISE DOS ACIDENTADOS DO ESTADO DE PERNAMANBUCO, BRASIL
}

\author{
Apresentação: Comunicação Oral \\ Júlio César Pinheiro Santos ${ }^{1}$; Valéria do Nascimento Félix ${ }^{2}$
}

\section{Resumo}

As ocorrências envolvendo os acidentes de trabalho provocados pelos riscos ambientais (biológicos, físicos, químicos) e de segurança (ergonômicos e de acidentes), são comuns em ambientes de zona rural. A maioria dos trabalhadores rurais que trabalham no campo não tem o hábito de comunicar esses eventos aos órgãos responsáveis pelo setor de segurança do estado, além disso, não tem conhecimentos na área de Segurança e Cultura de Prevenção a acidentes, envolvendo riscos ambientais e segurança. Esse trabalho objetivou analisar os acidentes do trabalho rural que são vinculados ao Hospital da Restauração (HR). Essa proposta foi elaborada a partir dos dados coletados durante o período de janeiro/2013 a dezembro/2015, através de levantamentos dos registros de acidentes: atividade ocupacional, situação do mercado de trabalhos e a descrição dos motivos dos acidentes. Os resultados apresentaram 61 casos de acidentes de trabalhos que foram provocados pelos riscos de segurança (acidentes). Observa-se que todos esses acidentes de trabalho que ocorrem na zona rural foram causados pelos seguintes motivos: acidente de trajeto, choque elétrico, violência, máquinas e quedas. Ficou constatado também que os funcionários classificados a partir da atividade ocupacional e pela situação de mercado de trabalho eram: agricultor, trabalhador da cultura de cana de açúcar e trabalhador volante de agricultura (atividade ocupacional) e registrado de carteira assinada, empregado não registrado, autônomo/conta própria, cooperativado, trabalhador avulso, outros e ignorado (situação de mercado de trabalho). Os dados acima mostram que o HR possui diferentes fatores causadores de ocorrências, provocadas pelos riscos de segurança (acidentes), não tendo política de gestão voltada para a Segurança, Cultura e Prevenção de acidentes de trabalho.

Palavras-Chave: Acidentes de trabalho; Áreas Agrícolas; Gestão de Segurança; Riscos de Segurança.

\footnotetext{
1 Graduado em Engenharia Ambiental, Universidade Católica de Pernambuco, juliocesarpsantos@gmail.com

2 Tecnóloga em Segurança do Trabalho, UNINTER, 1962nascimentovaleriafelix@gmail.com
} 


\section{Introdução}

Segundo dados da Organização Internacional do Trabalho (OIT), estima-se que os custos relacionados aos acidentes de trabalho e às doenças ocupacionais, são equivalentes a 4\% do Produto Interno Bruto (PIB) mundial, valendo aproximadamente 2,8 trilhões de dólares por ano, além disso cerca de 6,3 mil trabalhadores morrem diariamente, no mundo, devido a situações ligadas ao trabalho (RIBEIRO et al., 2015;). Ainda, o mesmo órgão afirma que, no mundo, as mortes que são causadas por doenças ou por acidentes de trabalho passaram de 2,31 milhões em 2003 para 2,34 milhões em 2008 (BEGNINI; ALMEIDA,2015).

No Brasil, segundo dados estatísticos do Ministério da Previdência Social, em 2013 foram registrados 717.911 casos de acidentes de trabalho, sendo: 559.081 acidentes de trabalhos (típico, de trajeto e doenças ocupacionais) e 158.830 acidentes de trabalho sem a Comunicação dos Acidente de Trabalho (CAT) registrada (BRASIL, 2016). No estado de Pernambuco, no mesmo ano, foram registrados 20.483 casos de acidentes de trabalho, sendo:13.548 acidentes considerados como típico, de trajeto e doenças ocupacionais e 6.935 acidentes sem a CAT registrada (BRASIL, 2016.).

Os acidentes de trabalho no setor rural, apresentam características que se relacionam com as principais atividades, como é o caso da região do Nordeste do Brasil, que apresenta atividades ligadas ao cultivo de cana-de-açúcar, cultivo de frutas e florestas plantadas (BEGNINI; ALMEIDA,2015).

Segundo Silva et al. (2001), o Brasil é o país campeão em subnotificações de acidentes do trabalho, constatando-se a dificuldade em quantificar com exatidão a ocorrência de acidentes no trabalho rural. Além disso, é importante lembrar que existe uma carência de informações a respeito de acidentes do trabalho no geral, já que a literatura científica que trata a respeito do tema seja limitada (DREBES et al.,2014). O autor ainda afirma que, quando se trata de acidentes do trabalho no meio rural, a situação é ainda mais crítica, tendo em vista a incompatibilidade entre a precariedade das pesquisas e a importância assumida pela temática.

Nesse contexto, o estudo objetiva analisar os acidentes do trabalho rural que são vinculados ao Hospital da Restauração (HR), PE, Brasil, durante o período de 2013 a 2015. A escolha da temática deu-se em função da existência dos acidentes de trabalhos que ocorrem no setor rural e também pela importância da prevenção da saúde dos trabalhadores rurais. Sendo assim, esse artigo apresenta e discute, em detalhes, os vários Acidentes de Trabalho 
ocorridos no HR, através dos diferentes tipos de riscos: ambientais (físico, químico, biológicos) e de segurança (ergonômicos e de acidentes).

\section{Fundamentação Teórica}

O trabalho agrícola possui um grande número de atividades diversificadas, que vão desde a limpeza e a preparação do solo para o plantio, como as operações de manejo da cultura, colheita, transporte e armazenamento, sendo operadas por ferramentas manuais, máquinas, implementos, veículos, produtos químicos e substancias inflamáveis (ACOSTA, 2015). Sendo assim, os trabalhadores da agricultura realizam atividades arriscadas e insalubres em ambientes que contém diversos tipos de riscos, tais como: riscos ambientais (biológicos, físicos, químicos) e riscos de segurança (acidentes e ergonômicos) (TEIXEIRA; FREITAS, 2003; SILVEIRA et al., 2005; ROBAZZI et al., 2006). Além disso, esses riscos favorecem a ocorrência de três situações distintas: acidentes do trabalho típicos (ocorrem no interior do ambiente de trabalho); acidentes de trajeto (acontecem no percurso da moradia ao trabalho) e doenças ocupacionais (são decorrentes das atividades exercidas no trabalho, bem como a exposição a um ambiente que cause algum dano à saúde do trabalhador) (KIRCHHOF et al., 2003).

$\mathrm{Na}$ evolução do trabalho rural no Brasil, percebe-se que os riscos ocupacionais já existiam, contudo foram intensificados e agravados a partir da década de 40 em função das transformações que afetaram o ambiente do trabalho rural, tendo como consequência o aumento da ocorrência de acidentes (DREBES et al., 2014). A modernização da agricultura, edificada sobre a difusão de tecnologias, aproximou o trabalho rural com o modelo de produção taylorista e fordista, com sua crescente fragmentação de tarefas e rotinização, bem como externalização de riscos, contribuindo para o desencadeamento de um modelo similar ao do trabalho urbano industrial, resultando em um processo de precarização das condições de trabalho e de desproteção social do trabalhador rural, e tendo como consequências diretas sobre sua saúde (GOMEZ; THEDIM-COSTA, 1999).

Com o passar do tempo, desde o período da modernização da agricultura, mudanças têm sido instituídas, e ainda nos dias atuais, os acidentes do trabalho no meio rural representam um problema social de relevância, que é agravado em virtude das subnotificações e da escassez de informações, as quais tendem a menosprezá-lo (DREBES et al.,2014). 


\section{Metodologia}

O estudo foi desenvolvido no HR, localizado no município de Recife, PE, Brasil. Órgão público vinculado à Secretaria Estadual de Saúde (SES) do governo do Estado de Pernambuco.

A pesquisa teve característica quantitativa do levantamento de dados, avaliação de acidentes e suporte técnico como fontes de prevenção a acidentes, se estruturando em duas etapas:

1) Inicialmente foi feito um levantamento dos registros sobre acidentes de trabalho com trabalhadores rurais: agricultor, trabalhador da cultura de cana de açúcar e trabalhador volante de agricultura, (atividades ocupacionais), empregado registrado com carteira assinada; empregado não registrado; autônomo/conta própria; outros e ignorado (situação de mercado de trabalho), tendo como fonte o banco de dados do HR;

2) Em seguida, os registros obtidos foram separados por diferentes tipos de acidentes de trabalho, parte do objetivo desta pesquisa, e identificados os motivos que ocasionaram os mesmos através da análise dos laudos de acidentes e do Manual de Normas e Rotinas do Sistema de Informação de Agravos de Notificação (SINAN) - Saúde do Trabalhador;

\section{Resultados e Discussão}

O levantamento dos acidentes de trabalho ocorridos em ambiente de zona rural, deu-se a partir dos dados obtidos do SINAN do HR, da qual foi realizado durante o período de janeiro/2013 a dezembro/2015. O resultado desse levantamento está apresentado na figura 1.

Figura1: Acidentes de trabalho ocorrido no ambiente rural - 2013 a 2015.

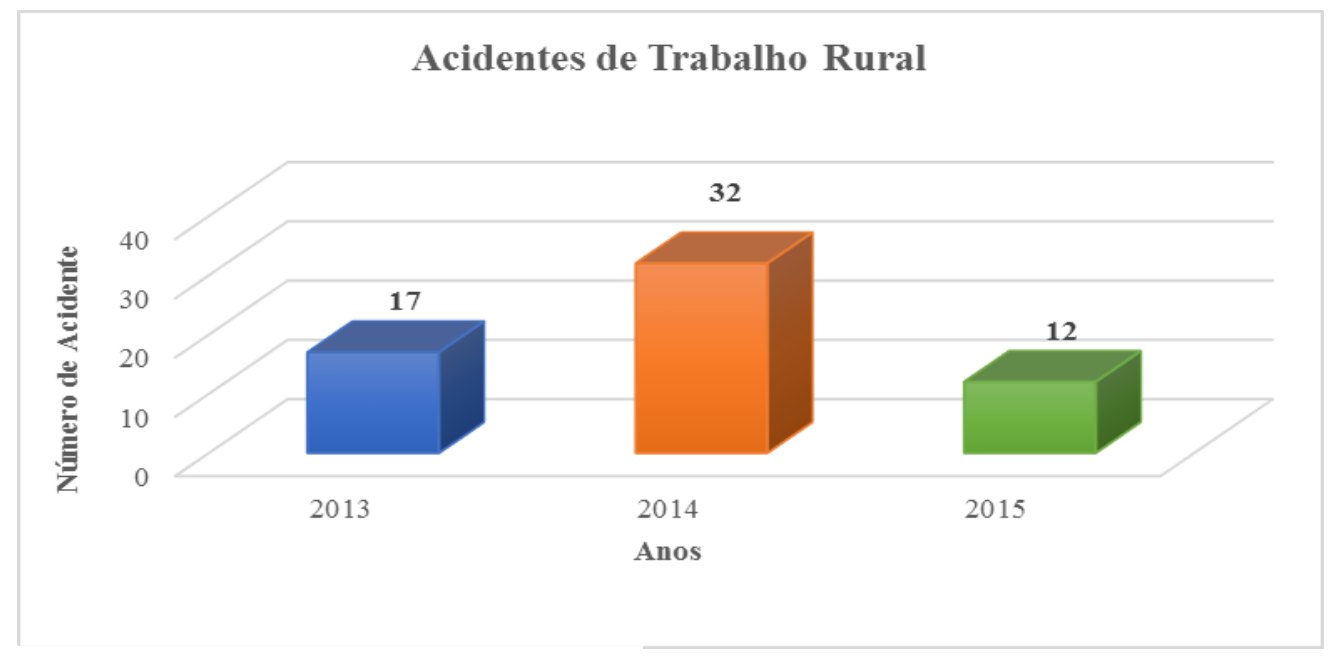

Fonte: Própria 
A Figura 1 mostra que, durante o período de janeiro/2013 a dezembro/2015, houveram 61 casos de acidentes de trabalho ocorridos na zona rural. Além disso, o ano de 2014, foi ano em que obteve o maior número de acidentes de trabalho no campo, seguido pelos anos de 2013 e 2015. Diante desse fato, pode-se concluir que todos os acidentes de trabalho em ambiente de zona rural, foram provocados por riscos de segurança (acidentes).

Conforme os dados analisados e extraídos da Figura 1, pode-se elaborar a Tabela 1 abaixo, que mostra a relação entre os números de acidentes de trabalho com a situação do mercado de trabalho dos trabalhadores rurais que tem ocupação relacionada a função de trabalhador volante de agricultura.

Tabela 1: Atividade e situação de mercado de trabalho dos funcionários do HR.

\begin{tabular}{l|l}
\hline Situação no Mercado de Trabalho & Número de acidentes \\
\hline Empregado registrado com carteira & 13 \\
assinada & 10 \\
Empregado não registrado & 1 \\
Autônomo contra própria & 16 \\
Cooperativado & 19 \\
Trabalhador avulso & 1 \\
Outros & 1 \\
Ignorados & $\mathbf{6 1}$ \\
\hline Total &
\end{tabular}

Fonte: Própria

De acordo com as informações apresentadas no Tabela 1, durante o período de 2013 a 2015 foram registrados 19 acidentes de trabalho envolvendo trabalhadores que tem a situação de mercado de trabalho caracterizada como trabalhador avulso, classificando-se como sendo o maior índice de acidente de trabalho no ambiente da zona rural.

O Tabela 1 demonstrou que os trabalhadores que têm a situação de mercado de trabalho classificada com trabalhador avulso, tiveram o segundo maior índice de acidente de trabalho durante o período de 2013 a 2015. Já os trabalhadores que têm a situação de mercado de trabalho classificada como Cooperativado, obtiveram o quarto maior índice de acidente de trabalho no ambiente da zona rural, durante os anos de 2013 a 2015. Entretanto, os trabalhadores que têm a situação de mercado de trabalho classificada como empregado registrado com carteira assinada, obtiveram o quinto maior índice de acidente de trabalho no ambiente da zona rural, em relação aos anos de 2013 a 2015. 
Já, para os casos dos trabalhadores que tem a situação de mercado de trabalho classificada como: autônomo; outros e ignorados, foi registrado 1 acidente de trabalho para cada tipo de mercado de trabalho, sendo assim, tornou-se o sexto maior índice de acidente de trabalho ocorrido no ambiente da zona rural, em comparação aos anos de 2013 a 2015.

A partir de dados analisados e extraídos da Figura 1, pode-se elaborar a Tabela 2, que mostra a comparação entre os números de acidentes de trabalho com o tipo de ocupação dos trabalhadores rurais:

Tabela 2: Mostra atividade de ocupação de trabalhadores rurais.

\begin{tabular}{ll}
\hline Ocupação & Número de acidentes \\
\hline Agricultor & 4 \\
Trabalhador da cultura de cana de açúcar & 12 \\
Trabalhador volante de Agricultura & 45 \\
\hline Total & $\mathbf{6 1}$ \\
\hline
\end{tabular}

Fonte: Própria

O resultado apresentado na Tabela 2, constata a presença de 45 acidentes de trabalho envolvendo trabalhadores da zona rural que tem ocupação relacionada a função de trabalhador volante de agricultura, entre anos de 2013 a 2015. Ainda de acordo com o Tabela 2, concluise que os 45 trabalhadores da zona rural têm a ocupação relacionada com a usina de cana de açúcar (trabalhador da cultura de cana de açúcar). Já para os casos de trabalhadores que atuam no campo e que por sua vez tem a ocupação de trabalho relacionado com os agricultores, apresentou-se 4 casos de acidentes de trabalho.

Com base nas informações obtidas através da Figura 1, foi elaborada uma planilha, relacionando os motivos que levaram a acometer os acidentes de trabalho na zona rural, com seus respectivos números. Conforme apresenta o Tabela 3:

Tabela 3: Descrição dos motivos de acidentes de trabalho ocorridos em ambientes de zona rural.

\begin{tabular}{ll}
\hline Motivos dos acidentes & Número de acidentes \\
\hline Acidente de Trajeto & 42 \\
Acidentes & 4 \\
Choque Elétrico & 1 \\
Violência & 2
\end{tabular}


Máquinas

Quedas

9

\section{Total}

61

Fonte: Própria

Pode se afirmar que os acidentes de trajeto ocorridos pelos trabalhadores rurais, representou 68,85\% quando comparado aos demais motivos de acidentes de trabalho. Para os casos de acidentes de trabalho envolvendo quedas pelos trabalhadores rurais, chegou a $14,75 \%$ quando comparado aos demais motivos de acidentes de trabalho. Já para os casos de acidentes de trabalho envolvendo acidentes pelos trabalhadores rurais, representou 6,55\%.

Os acidentes de trabalho envolvendo: máquinas, violência e choque elétricos, ocorridos pelos trabalhadores rurais, representaram 4,91\%;3,27\%; $1,63 \%$ quando comparado aos demais motivos de acidentes de trabalho.

\section{Conclusões}

O presente estudo, apresentou ferramentas de extrema importância para mitigação dos riscos e dos acidentes do trabalho com trabalhadores rurais.

Devido a presença de acidentes de trabalho na zona rural, ainda hoje se dá pouca importância para os estudos na área de acidentes de trabalho provocados pelos riscos ambientais e riscos de segurança. Além disso, um dos fatores que contribui para esse baixo índice de interesse, é a falta de capacitação profissional sobre as normas de segurança do trabalho dos trabalhadores de classe social baixa, contribuindo para que os trabalhadores rurais não cobrem os seus diretos trabalhistas aos patrões (empregador), e por consequência disso, não investem nos seus funcionários, colaborando com a presença de novos acidentes de trabalhos. Também existe outro fator que contribui para esse baixo índice de interesse é a questão do trabalhador rural que faz o seu próprio cultivo e por estar isolado da sociedade, não tem a capacitação profissional necessária sobre as normas de segurança do trabalho, e consequentemente não tenha a prevenção da sua saúde.

Os resultados, mostram que no período entre janeiro/2013 a dezembro/2015 aconteceram 61 casos de acidentes de trabalho registrados, dos quais todos os casos foram provocados pelos riscos de segurança de acidentes. Entretanto, os acidentes no período de janeiro/2013 a dezembro/2015, foram causados pelos seguintes motivos: acidente de trajeto, acidentes, choque elétrico, violência, máquinas e quedas. 
A partir dos resultados obtidos pelos riscos de segurança (acidentes), os funcionários que estavam envolvidos nesse tipo em especial, foram analisados e identificados, de acordo com a sua respectiva ocupação profissional e situação de mercado de trabalho, classificando como sendo: agricultor, trabalhador da cultura de cana de açúcar e trabalhador volante de agricultura (ocupação profissional), empregado registrado com carteira assinada; empregado não registrado; autônomo/conta própria; outros e ignorado (situação de mercado de trabalho).

Para trabalhos futuros, é importante considerar a realização de novas pesquisas relacionadas a acidentes de trabalho provocados pelos riscos ambientais e de segurança.

\section{Referências}

ACOSTA, E, M. Gestão de riscos ocupacionais do setor agrícola no município de ChapecóDiagnóstico. 2015. 35p. Monografia (Especialização em Engenharia de Segurança do Trabalho). Chapecó (SC): Universidade do Oeste de Santa Catarina; 2015.

BEGNINI, S; ALMEIDA, L.E.D.F Acidentes de trabalho no meio rural: perfil do trabalhador acidentado em Santa Catarina, Brasil. Rev. Eletrônica Gestão de Saúde, Vol. 06, $\mathrm{n}^{\circ} .03$, p.2538-52. 2015.

BRASIL. Ministério do Trabalho e Emprego. Anuário Estatístico de Acidente do Trabalho: AEAT 2013. Disponível em: $<$ http://www.previdencia.gov.br/dados-abertos/aeps2013-anuario-estatistico-da-previdencia-social-2013/aeps-2013-secao-iv-acidentes-dotrabalho/aeps-2013-secao-iv-acidentes-do-trabalho-tabelas/>.Acesso em: 22 set.2016.

DREBES, L.M. et al. Acidentes típicos do trabalho rural: um estudo a parti dos registros do hospital universitário de Santa Maria, Rs, Brasil. Rev. Monografias Ambientais, Santa Maria, Vol. 13, n.4, p. 3467-3476. 2014.

GOMEZ, C. M.; THEDIM-COSTA, S. M. da F. Precarização do trabalho e desproteção social: desafios para a saúde coletiva. Ciência \& Saúde Coletiva, v. 4, n. 2, p. 411-421, 1999.

KIRCHHOF, A. L. C. et al. Os acidentes de trabalho atendidos em pronto-atendimento de hospital universitário. Escola Anna Nery Revista de Enfermagem, v. 7, n. 3, p. 361 - 368, 2003.

RIBEIRO, F.H., et al. Acidentes de trabalho e sua associação com os fatores idade e tempo de experiência do trabalhador: uma pesquisa documental com base no cadastro do sistema SINAN. In: XXXV ENCONTRO NACIONAL DE ENGENHARIA DE PRODUCAO, 2015, Fortaleza. Anais eletrônicos... $\quad$ Fortaleza: Disponível em:< http://www.abepro.org.br/biblioteca/TN_STO_209_238_27787.pdf>. Acesso em: 23 set.2016.

ROBAZZI, M. L. do C. C. et al. Acidentes de trabalho identificados em prontuários hospitalares. Ciência, cuidado e saúde, v. 5, n. 3, p. 289 - 298, set./dez. 2006. 
SILVA, J. R. et al. Acidentes graves no trabalho rural entre 1994 e 1997 na região centro-sul do estado de São Paulo, Brasil. Revista Instituto Florestal, São Paulo, v. 13, n.1, p. 83-97, 2001.

SILVEIRA, C. A.; ROBAZZI, M. L. do C. C.; MARZIALE, M. H. P.; DALRI, M.C. B. Acidente de trabalho entre trabalhadores rurais e da agropecuária identificados através de registros hospitalares. Ciência, cuidado e saúde, v. 4, n. 2, p. 120 - 128, maio/ago. 2005.

TEIXEIRA, M. L. P.; FREITAS, R. M. V. de. Acidentes do trabalho rural no interior paulista. São Paulo em Perspectiva, v. 17, n. 2, p. 81-90, 2003. 